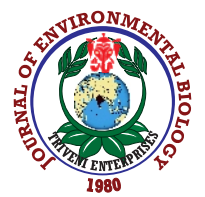

\title{
Prevalence of malnutrition and associated factors of pond fish farmers from Noakhali Coast, Bangladesh
}

\author{
F.H. Pingki', M.B. Hossain ', S. M. Nurul Amin', M. Sultana ${ }^{3}$, M.M. Islam ${ }^{4}$, A.F.M. Arifur Rahman', A.U. Nur' and Aziz Arshad ${ }^{2 *}$ \\ 'Department of Fisheries and Marine Science, Noakhali Science and Technology University, Noakhali-3814, Bangladesh \\ ${ }^{2}$ International Institute of Aquaculture and Aquatic Sciences, Universiti Putra Malaysia, 71050 Port Dickson, Sembilan, Malaysia \\ ${ }^{3}$ Department of Food Technology and Nutrition Science, Noakhali Science and Technology University, Noakhali-3814, Bangladesh \\ ${ }^{4}$ Nutrition Unit, Bangladesh Agricultural Research Council, Farmgate, Dhaka-1200, Bangladesh \\ *Corresponding Author Email : azizarshad@upm.edu.my
}

\begin{abstract}
Aim: Current investigation was conducted to elucidate the occurrence of malnutrition and related factors of pond fish farmers from Noakhali coast, Bangladesh.

Methodology: Eighty male pond fish farmers, aged 18-70 years, from Noakhali Sadar, Subarnachar, Kobirhat and Ramgati upazila of Noakhali coast, Bangladesh were selected randomly for the investigation. Data were collected through questionnaire interview and survey, focus group discussion, cross check interviews, Body Mass Index, Mid Upper Arm Circumference and blood Hb level. Pearson correlation was used to determine the association between anthropometric and socio-demographic characteristics and simple linear regression were fitted to identify factors associated with malnutrition among pond fish farmers.
\end{abstract}

Results: The overall prevalence of malnutrition, overweight, obesity of pond fish farmers were $18.8 \%, 21.2 \%$ and $17.5 \%$, respectively, based on BMI while the prevalence of malnutrition was $23.7 \%$ as per MUAC. The prevalence of mild anaemia (57.5\%) was high compared to the global anaemia prevalence. $10 \%$ had no education while $22.5 \%, 20 \%, 7.5 \%$ and $5 \%$ had primary, secondary, higher secondary and bachelor education level, respectively. The highest (38.8\%) annual income of the pond fish farmers was 1,300-1,785 USD. Significant variations (tested by one-way ANOVA) in nutritional status and socio-demographic characteristics were observed. Pearson correlations of age with MUAC exhibited significant $(r=-0.271 ; p<$ $0.05)$ negative association, BMI was found positively and significantly correlated with annual income $(r=0.223 ; p<0.05)$ and MUAC $(r=0.246 ; p<0.05)$ Linear regression analysis revealed that the age of pond fish farmers had negative significant influence on MUAC and positive impact of annual income on BMI.

Interpretation: The prevalence of malnutrition, mild anaemia with poor economic status were high among the pond fish farmers of Noakhali Coast. Therefore, community based health and nutritional education, effective public health and nutritional intervention programs, poverty alleviation program and economic growth may improve the overall health, nutritional knowledge and thus status of pond fish farmers.

Keywords: Body mass index, Economic growth, Fish farmers, Homestead ponds, Malnutrition
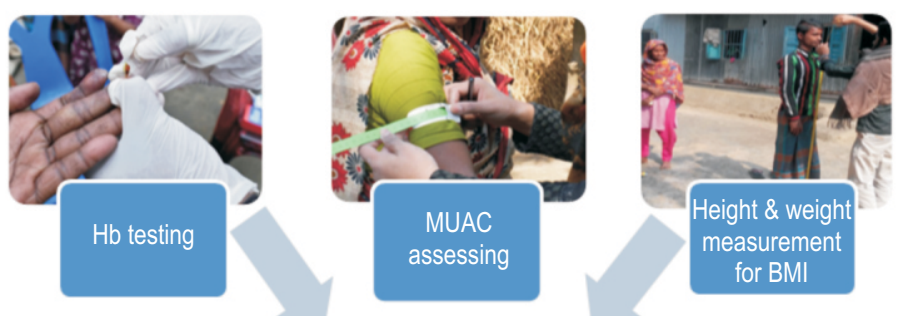

How to cite : Pingki, F.H., M.B. Hossain, S.M.N. Amin, M. Sultana, M.M. Islam, A.F.M. Arifur Rahman, A.U. Nur and A. Arshad: Prevalence of malnutrition and associated factors of pond fish farmers from Noakhali Coast, Bangladesh. J. Environ. Biol., 41, 1171-1178 (2020). 


\section{Introduction}

Malnutrition remains to be the foremost public health problems in Bangladesh. Infectious diseases like acute respiratory diseases and diarrheal diseases are responsible for most nutrition-related health problems in this country (Gross et al., 2000). Due to malnutrition, anemia probably is another major public health issue in all developing counties (UNICEF, 2013). There are several reasons for prevalence of anaemia in a population, like deficiency of iron and other nutritional deficiencies of folate, Vitamin $B_{12}$ and Vitamin $A$ parasitic infections, acute and chronic inflammation, and acquired disorders that affects the haemoglobin production or survival of red blood cell (WHO, 2011).

In our society, fishermen are underprivileged and considered as one of the poorest segments (Rahman et al., 2012). Malnutrition depends on some factors like economic, ecological, social and others, therefore varies from country to country. There are some major reasons for high prevalence of malnutrition like poor sanitation and drinking water facilities, poverty, fluctuation in annual income. A close link exists between education of a pond fish farmer with their income and their wellbeing. As per Bangladesh Demographic and Health Survey (Biswas et al., 2017) report, 29.1\%, males were underweight, overweight and $3 \%$ obese. Recently in Bangladesh, to meet the nutritional demand of Sustainable Development Goals (SDG) there has been making an attempt in reducing malnutrition problems.

Nutritional status depends on food intake and health status. Food consumption, which mostly depends on production, access, distribution as well as financial ability, effects the health and nutritional status of population (UNICEF, 2013). The nutritional aspect of food security is attained when secure access to food can be ensured with a hygienic environment, satisfactory health service, income, and educated care to ensure a healthy life for all household members (Gross et al., 2000). An anthropometric measurement such as Body Mass Index (BMI) and Mid Upper Arm Circumference (MUAC) are two useful indicators that record the nutritional status of pond fish farmers that lives under poor economic condition (WHO, 1995). Even though nutritional and health status of adult pond fish farmers can be assessed in many ways, BMl is most commonly used due to its inexpensiveness, non-invasion and suitability for large-scale surveys (Pirlich and Lochs, 2001; Lee and Nieman, 2007). Usually, BMI is considered as a good measurement index not only of the nutritional status but also the socio-economic status of pond fish farmers in developing countries (Kongsdier, 2002; Adak et al., 2006). MUAC is other feasible tool for assessing the nutritional status because it is comparatively easy to use, requires minimum equipment as well as quick calculations, and inexpensive and simply transportable. It is particularly considered as efficacious tool for assessing the malnutrition in adult pond fish farmers.
Several studies have been conducted on anthropometric characteristics, nutritional status and prevalance of anaemia in adult males (Monteiro et al., 2004; Sultana et al., 2015; Banik, 2008; Tonder et al., 2018; Shahabuddin et al., 2000; Ahmed, 2000; Shill et al., 2014; Hyder et al., 2004; Hyder et al., 2001; Heck et al., 2008). However, information on the nutritional status of males in Bangladesh is meagre (Sultana et al., 2015). Besides, these studies were based on the conventional indicators of nutritional status. Hence, direct measure of height or weight could not be measured to underestimate the prevalence of malnutrition in adult male that could have impacted the precision of the findings. Moreover, the limitations of previous studies were unavailability of blood markers like HemoCue or other device that could be used for acquiring more accurate results on the concentration of haemoglobin. To date, no study on nutritional health status of pond fish farmers has been assessed in the Noakhali coastal area. Therefore, considering the knowledge gap and above mentioned importance the present study was conducted to assess the prevalence of malnutrition and associated factors in pond fish farmers of Noakhali coast, Bangladesh.

\section{Materials and Methods}

Study site: The present study was executed in eight unions from four upazilas of Noakhali Coast based on collection of data from 80 pond fish farmers during the period $6^{\text {th }}$ November, 2018 to $7^{\text {th }}$ January, 2019 (Fig. 1).

Data collection: A draft questionnaire was developed and pretested with few pond fish farmers before collecting primary data. The final questionnaire was then pre-tested, improved and modified. The questionnaire included anthropometric characteristics (Height, weight, MUAC), anaemia prevalence $(\mathrm{Hb}$ level) and socio-demographic (sex, age, religion, education, annual income) characteristics of pond fish farmers. Secondary data on nutritional health were gathered from books, from various published and unpublished relevant documents of various sources, journal articles, government and non government organizations like District Fisheries Office, Central Library of Noakhali Science and Technology University.

Height and weight was measured using ideal height and weight measuring scale (H07, Zhongshan Dingheng Yipin Home Product Co. Ltd., Chaina). While measuring the weight, individuals were requested to be bare footed and put off heavy clothes, and weight was logged in to the nearest $0.5 \mathrm{~kg}$, for measuring, height individuals were positioned to stand on plain land, bare foot looking straight. Height was recorded to the nearest $0.1 \mathrm{~cm}$. Nutritional health condition was calculated by estimating the Body Mass Index (BMI) by the following formula and classified according to "Asian criteria" (WHO, 2000; Llido and Mirasol, 2011). 


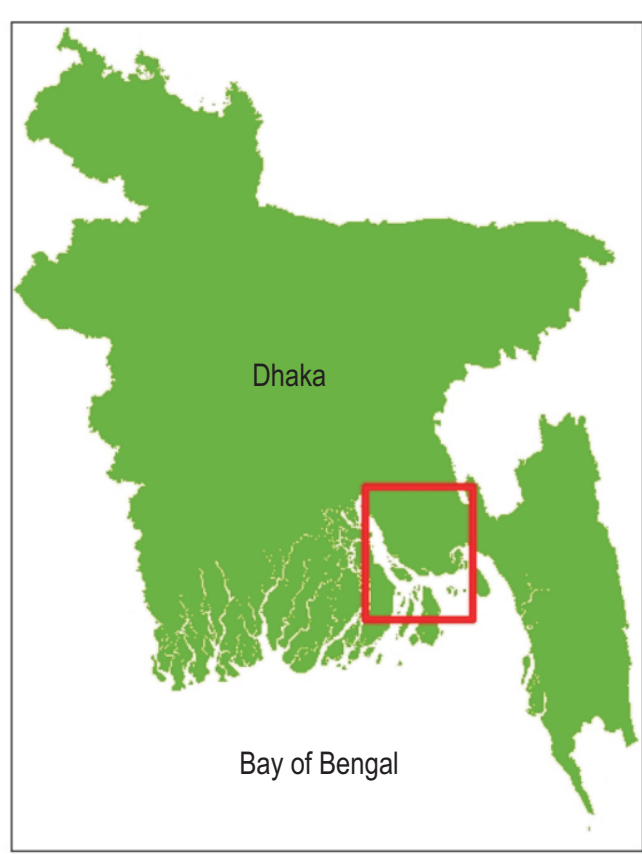

Legend

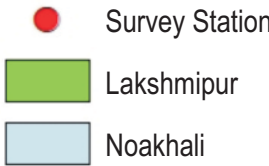

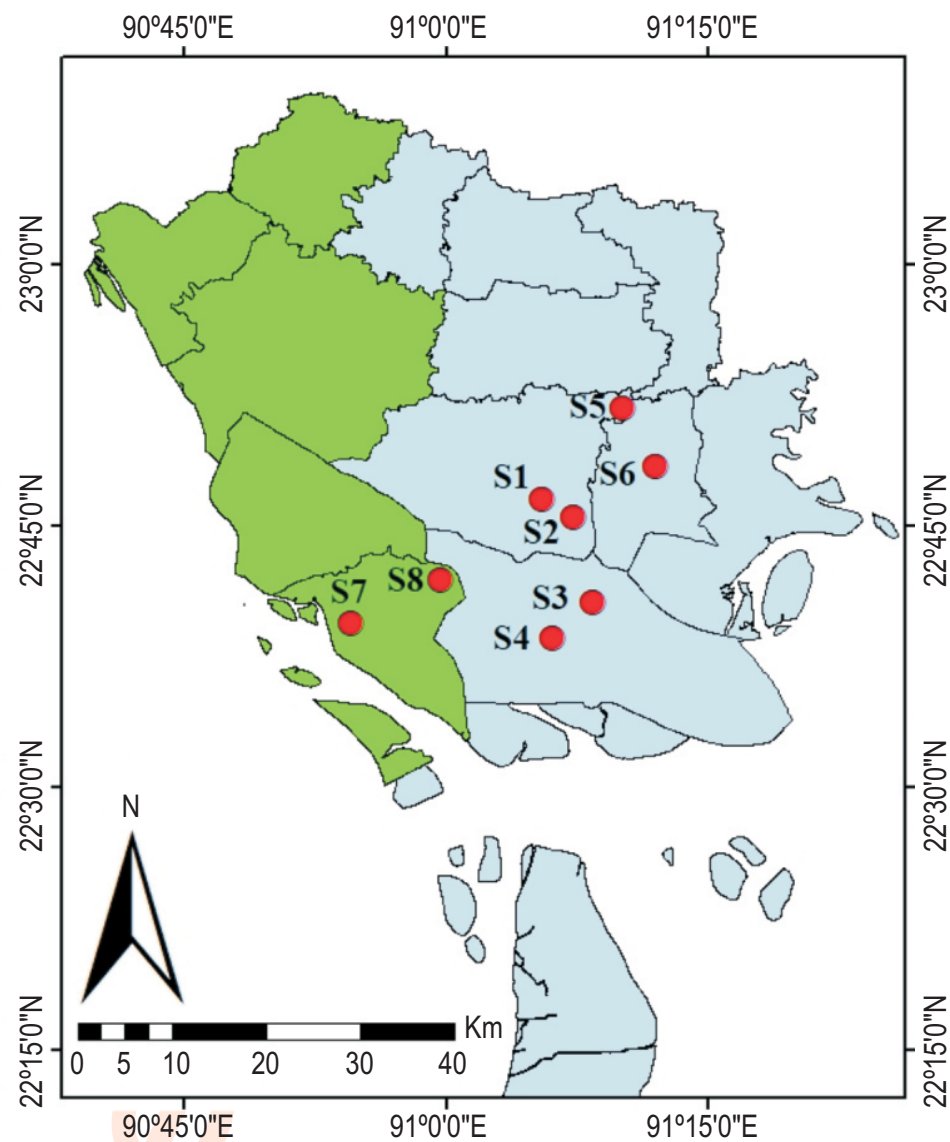

Fig. 1: Map showing the study sites. $\left(S_{1}, S_{2}\right.$ indicates Noakhali Sadar, $S_{3}, S_{4}$ indicates Subarnachar, $S_{5}, S_{6}$ indicates Kobirhat and $S_{7} S_{8}$ indicates Ramgati).

$$
\mathrm{BMI}=\frac{\text { Weight in kilograms }}{(\text { Height in meters })^{2}}
$$

MUAC value was calculated to the nearest $0.1 \mathrm{~cm}$ with a tape, and measurement was taken at theme-point of the upper left arm. After locating the mid-point, the subjects were asked to keep their arm extended with palm facing inward. The tape was wrapped smoothly and gently around the mid-point of arm, and MUAC was classified according to James et al. (1994), Tang et al. (2013) and Ulijaszek and Kerr (1999).

During the study, the blood samples were collected to assess the prevalence of anaemia by a nurse who was trained for two days. Anemia prevalence was assessed by determining the haemoglobin level (gdl') as per WHO (1992; WHO, 2001) using Hemoglobin analyzer (HemoCue $\mathrm{Hb} \mathrm{201}{ }^{+}$, HemoCue AB, Sweden).

Data processing and analysis: One-way analysis of variance (ANOVA) was conducted to test the difference in the mean anthropometric characteristics. Simple linear regression and Pearson correlation coefficients $(r)$ were used to elucidate the interrelationship between anthropometric and sociodemographic characteristics. Age and annual income were used as continuous independent variable in these analyses. Data were evaluated by software SPSS (Statistical Package for Social Science) version 25 .

\section{Results and Discussion}

The perusal of data of body mass index revealed that $18.8 \%$ of pond fish farmers living in the investigated area were underweight and $21.2 \%$ overweight, while $17.5 \%$ were pre-obese and obese (Table 1). Only $5 \%$ pond fish farmers suffered from obesity at Kobirhat upazila (Fig. 2). However, the underweight $(25 \%)$ were more prevalent at Noakhali Sadar upazila than those of other upazilas (Fig. 2). The highest (30\%) and lowest (15\%) overweight were formers found at Kobirhat and Ramgati upazila, respectively. The present study demonstrated that the incidence of overweight $(21.2 \%)$, pre-obesity and obesity $(17.5 \%)$ were high compared to the National Demographic and Health Survey (BDHS) in Bangladesh (Biswas et al., 2017) because the previous study wasn't conducted specially with pond fish farmers of Noakhali Coastal region. The present findings revealed that the 
Table 1 : Prevalence of nutritional status according to Body mass index (BMI), Mid upper arm circumference (MUAC) and haemoglobin level among the pond fish farmers

\begin{tabular}{lll}
\hline BMI Range $\left(\mathrm{kg} \mathrm{m}^{-2}\right)$ & Nutritional status & $\mathrm{n}(\%)$ \\
\hline$<18.5$ & underweight & $15(18.8)$ \\
$18.5-22.99$ & Normal & $34(42.5)$ \\
$23.0-24.99$ & Overweight & $17(21.2)$ \\
$\geq 25.0$ & $14(17.5)$ & \\
Pre-obese and obese & & $80(100)$ \\
Total & Nutritional status & $\mathrm{n}(\%)$ \\
\hline MUAC $(\mathbf{c m})$ & Normal & $61(76.3)$ \\
\hline$\geq 23.0$ & Malnutrition & $19(23.7)$ \\
$<23.0$ & & $80(100)$ \\
\hline Total & Anaemia status & $\mathrm{n}(\%)$ \\
\hline Haemoglobin level $\left(\mathbf{g d l}^{-1}\right)$ & Mild anaemia & $46(57.5 \%)$ \\
\hline $10-12.99$ & Nonanaemia & $34(42.5)$ \\
$\geq 13$ & & $80(100)$ \\
\hline Total & &
\end{tabular}

pond fish farmers were worse off. Von Tonder et al. (2018) elucidated Body Mass Index as a viable tool for identifying malnutrition in the Eastern Cape of South Africa and reported $16.9 \%$ population as overweight and 18.4 obese.

Nutritional status assessment based on cut off points of MUAC also indicated that $23.7 \%$ farmers suffered from malnutrition (Table 1). The highest (40\%) and lowest (10\%) number of farmers with malnutrition were reported from Noakhali Sadar and Ramgati upazila (Fig. 3). From the present study, it was found that the prevalence of malnutrition (23.7\%) was comparatively higher than that reported by Von Tonder et al. (2019) in South Africa. The present findings varied with reports of Banik (2008) in Jharkhand, India as the study area was different.

The prevalence of malnutrition of pond fish farmers with poor economic status compared with Health Survey at national levels (Biswas et al., 2017) as well as other countries (Von Tonder et al., 2018). This difference might be due to usint conventional methods which underestimated the nutritional status. Direct measures of weight or height could not be measured as the participants weren't ambulant, and some of them were unable to recollect their usual body weight. In such conditions, BMI was assessed and this could have affected the precision of the findings.

The perusal of data revealed that $57.5 \%$ farmers were found mild anaemic having haemoglobin level 10-12.99 $\mathrm{gdl}^{-1}$ (Table 1), while the highest $\mathrm{Hb}$ level $(75 \%)$ was reported from Noakhali Sadar and lowest (45\%) from Ramgati upazila (Fig. 4). Hyder et al. (1998) found $51 \%$ mild anaemic male having haemoglobin level 10-12.99 $\mathrm{gdl}^{-1}$ in a rural community of
Bangladesh. Heck et al. (2008) reported 5.7\% men anemic having less than $12 \mathrm{~g} \mathrm{dl}^{-1}$ hemoglobin in Bangladesh. Kassebaum et al. (2014) conducted a study on global anemia burden from 1990 to 2010 and found that global anemia occurrence in 2010 was $32.9 \%$, and the occurrence lowered in both sexes from 1990 to 2010. De Benoist et al. (2008) studied the occurrence of anaemia 1993-2005 worldwide and found that global anaemia occurrence in men was $12.7 \%$. Compared to national and regional studies (Hyder et al., 1998; De Benoist et al., 2008), the occurrence of mild anaemia (57.5\%) was reported to be higher in this study.

Based on the age, farmers were categorized into three groups: $20-35$ years-old as young, $36-50$ year as middle aged and 51-70 year as old (Table 2). It was found that middle aged group was maximum $(38.8 \%)$ and old was minimum $(31.1 \%)$ considering all farmers. This findings are somewhat in line with the findings of Ali et al. (2009) who conducted a study in Mymensingh and stated that most fish farmers (50\%) belonged to age group of 31 to 40 years which is in agreement with the present findings. In the study area, the major population of fish farmers $(81.3 \%)$ were Muslims. Khatun et al. (2013) also reported that Muslims and Hindus comprised $82 \%$ and $18 \%$ of the pond fish farmers, respectively.

Education is important for human existence as both education and society are interrelated and interdependent. Improvement and progress of an area largely depends on the quality of education. The study revealed that $10 \%$ population was illiterate, $35 \%$ could only sign, $22.5 \%$ had primary education, $20 \%$ secondary education, and the remaining were under graduates. This finding was compared with some other studies conducted in Bangladesh 


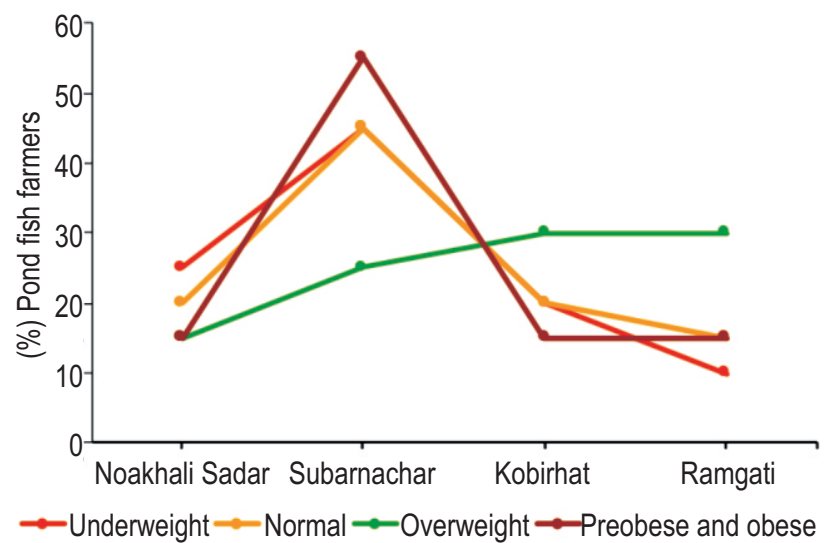

Fig. 2 : Prevalence of malnutrition of the study areas based on MUAC (cm).

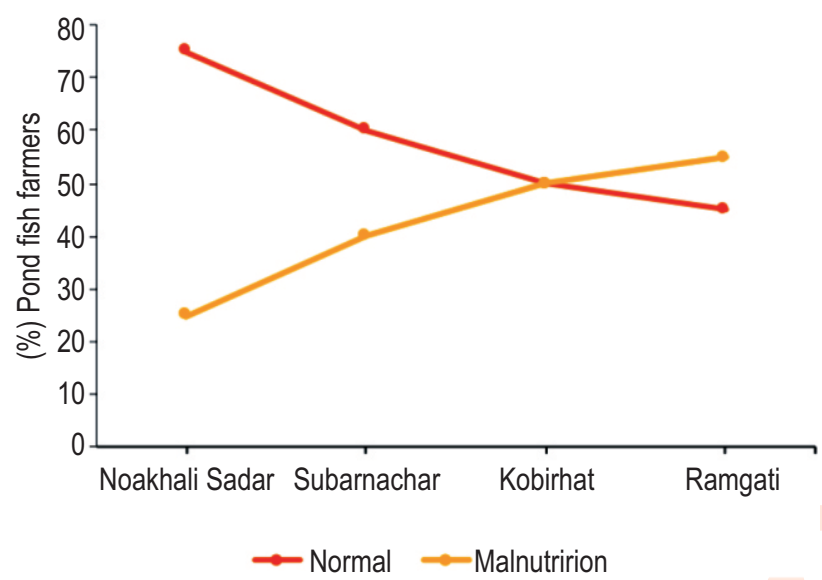

Fig. 3 : Prevalence of malnutrition of the study areas based on Body mass index.

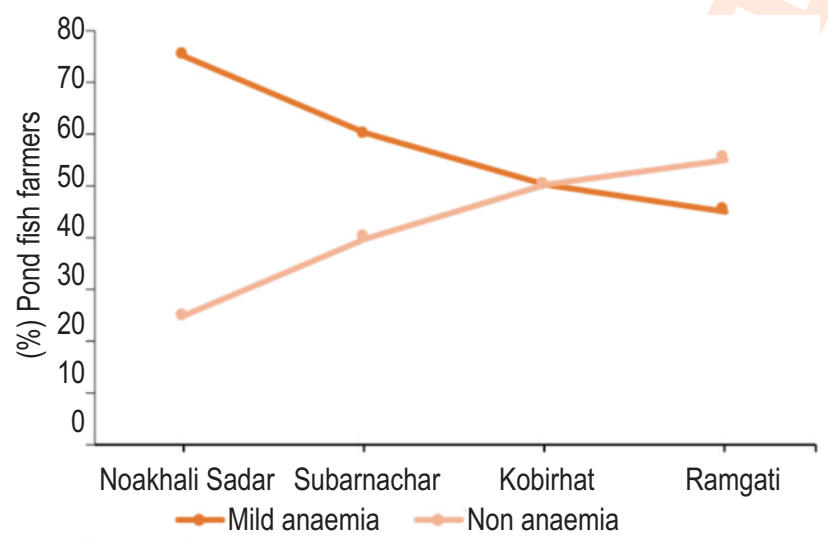

Fig. 4 : Prevalence of anemia in the study areas based on haemoglobin level $\left(\mathrm{g} \mathrm{dl}^{-1}\right)$.

(Fagun et al., 2020; Hossen et al., 2020; Khatun et al., 2013) where literacy rate was found higher in fish farmers than the national adult literacy rate $(65 \%)$ which strongly supported the present outcome.
Based on the annual income, pond fish farmers were classified into five categories (Table 2). The $1^{\text {st }}$ category included the pond fish farmers having annual income up to 365-845 USD. The $2^{\text {nd }}, 3^{\text {rd }}, 4^{\text {th }}$ and $5^{\text {th }}$ categories had annual income of $845-1,300$ USD; 1,300-1,785 USD; 1,785-2,260 USD and 2,260-2,500 USD, respectively ( $1 \mathrm{USD}$ is equivalent to $84 \mathrm{BDT}$ ). The highest percentage (38.8\%) pond fish farmers earned USD 1,300-1,785 per year. Among the four upazila, maximum (60\%) pond fish farmers from Ramgati upazila earned about 1300-1785 USD per year whereas only $25 \%$ of pond fish farmers from Noakhali Sadar upazila could earn that. It revealed that annual income of pond fish farmers was lower in Noakhali Sadar upazila than those of other. Therefore, the need of investment to provide facilities for improving education, knowledge about fish farming, health care facilities, proper sanitation etc. in Noakhali Sadar is crucial. However, it was observed that a total $38.8 \%$ of pond fish farmers from this studied area earned about 1300-1785 USD per year which was better from the findings of Khatun et al. (2013).

Analysis of Variance (ANOVA) was carried out to assess significant variation in the mean value of variables among the four selected upazila $(p<0.05)$ (Table 3$)$. ANOVA result showed that the mean religion, annual income of pond fish farmers varied among the four selected upazila $(p<0.05)$. However, no significant variation in the mean age, education, BMI, MUAC and Hb level $(p<0.05)$ was noted.

In order to investigate the association of nutritional status and socio-demographic variables Pearson correlation was conducted (Table 4). It showed no statistically significant correlation between the nutritional status and socio-demographic variables, except for MUAC, BMl, age and annual income $(P<$ $0.05)$. Age showed intermediate negative relationship with MUAC $(r=-0.271 ; p<0.05)$, BMI displayed positive significant association with MUAC $(r=0.246 ; p<0.05)$ and annual income $(r$ $=0.223 ; p<0.05$ ).

Simple linear regression was calculated explored to elucidate the effect of age on MUAC and annual income on BMI (Table 5) with increase in age of farmers each year, the farmer lost $5.6 \mathrm{~cm}$ of MUAC cut-off points. The results showed that a significant section of pond fish farmers were suffering from malnutrition, overweight and obesity. It is obvious that as they grew older, the pond fish farmers became nutritionally worm off. The annual income showed positive and significant correlation with BMI $(r=0.223 ; p<0.05)$. It appeared as higher the annual income of pond fish farmers, greater was BMI with increase in one USD of annual income of each farmer, the farmer gained $0.0001991 \mathrm{BMI}$. It indicates that the pond fish farmers continued with poor economic condition which impacts nutritional status. The prevalence of malnutrition, mild anaemia with poor economic status was high among the pond fish farmers of Noakhali Coast. 
Table 2 : Socio-demographic characteristics of pond fish farmers in the study area

\begin{tabular}{lll}
\hline Variables & Frequency & Percentage (\%) \\
\hline Age(Year) & 16 & 20 \\
$20-35$ & 31 & 48.8 \\
$36-50$ & 33 & 41.2 \\
$51-70$ & & \\
Religion & 65 & 81.2 \\
Muslim & 15 & 18.8 \\
Hindu & & \\
Education & 8 & 10 \\
Illiterate & 28 & 35 \\
Only sign & 18 & 22.5 \\
Primary & 16 & 20 \\
Secondary & 6 & 7.5 \\
Higher secondary & 4 & 5 \\
Bachelor & & \\
Annual income (USD) & 7 & 8.8 \\
$365-845$ & 27 & 33.8 \\
$845-1,300$ & 31 & 38.8 \\
$1,300-1,785$ & 12 & 15 \\
$1,785-2,260$ & 3 & 3.8 \\
$2,260-2,500$ & &
\end{tabular}

Table 3 : Analysis of Variance (ANOVA) for comparing mean value of variable among pond fish farmers (Mean \pm SD)

\begin{tabular}{|c|c|c|c|c|c|c|}
\hline \multirow[t]{2}{*}{ Variables } & \multicolumn{4}{|c|}{ Mean \pm SD } & \multirow[t]{2}{*}{$\mathbf{F}$} & \multirow[t]{2}{*}{ PValue } \\
\hline & Noakhali Sadar & Subarnachar & Kobirhat & Ramgati & & \\
\hline $\mathrm{BMI}\left(\mathrm{kg} / \mathrm{m}^{2}\right)$ & $20.65 \pm 3.11$ & $2.53 \pm 2.89$ & $23.35 \pm 4.13$ & $22.32 \pm 3.07$ & 2.369 & 0.077 \\
\hline $\operatorname{MUAC}(\mathrm{cm})$ & $22.92 \pm 2.78$ & $23.90 \pm 2.02$ & $24.45 \pm 2.48$ & $24.59 \pm 1.92$ & 2.128 & 0.104 \\
\hline Hb level $\left(\mathrm{gdl}^{-1}\right)$ & $12.44 \pm 0.90$ & $12.95 \pm 1.04$ & $12.72 \pm 0.64$ & $12.81 \pm 0.89$ & 1.215 & 0.310 \\
\hline Age (year) & $51.95 \pm 11.94$ & $44.35 \pm 11.45$ & $49.25 \pm 9.93$ & $44.30 \pm 11.54$ & 2.270 & 0.087 \\
\hline Religion & $1.25 \pm 0.44$ & $1.35 \pm 0.48$ & $1.15 \pm 0.36$ & $1.15 \pm 0.36$ & 3.123 & 0.031 \\
\hline Education & $3.55 \pm 3.98$ & $5.35 \pm 4.57$ & $7.05 \pm 5.06$ & $7.05 \pm 5.06$ & 2.262 & 0.088 \\
\hline $\begin{array}{l}\text { Annual income } \\
\text { (USD) }\end{array}$ & $1183.095 \pm 354.26$ & $1528.15 \pm 444.95$ & $1408.33 \pm 310.39$ & $1408.33 \pm 310.39$ & 4.399 & .007 \\
\hline
\end{tabular}

Table 4 : Association between nutritional status and socio-demographic characteristics

\begin{tabular}{llll}
\hline Variables & Correlations with & $r$ & Significance $(\mathrm{P}<)$ \\
\hline Age & BMl & 0.025 & 0.826 \\
& MUAC & -0.271 & 0.015 \\
BMl & MUAC & 0.246 & 0.028 \\
Annual Income & BMI & 0.223 & 0.047 \\
\hline
\end{tabular}

Table 5: Simple linear regression of anthropometric characteristics with age among pond fish farmers

\begin{tabular}{|c|c|c|c|c|c|c|c|c|}
\hline & \multicolumn{2}{|c|}{$\begin{array}{l}\text { Unstandardized } \\
\text { coefficients }\end{array}$} & \multirow{2}{*}{$\begin{array}{l}\text { Standardized } \\
\text { coefficients } \\
\text { Beta }\end{array}$} & \multirow[t]{2}{*}{$t$} & \multirow[t]{2}{*}{ Sig } & \multirow[t]{2}{*}{$\mathbf{R}$} & \multirow[t]{2}{*}{$\mathrm{R}^{2}$} & \multirow[t]{2}{*}{ Adjusted $R^{2}$} \\
\hline & B & Std. Error & & & & & & \\
\hline Age & -0.056 & 0.023 & -0.271 & -2.486 & 0.015 & 0.271 & 0.73 & 0.62 \\
\hline Annual income & 0.0001991 & 0.000 & 0.223 & 2.021 & 0.047 & 0.223 & 0.050 & 0.038 \\
\hline
\end{tabular}

Dependent variable: MUAC (cm), BMI $\left(\mathrm{kg} \mathrm{m}^{-2}\right)$; B= Regression coefficient (Parameter estimate), Std. Error = Standard Error, Beta = Beta coefficient of estimated regression. 
The nutritional status mostly relies on the availability of nutritious food in the household. Due to low income and poor education they are deprived of nutritious food. In developing countries like Bangladesh, low income level does not permit the type and amount of nutritious food available for consumption. It is unfortunate that maximum pond fish farmers are not aware of anaemia. Proper health education to develop knowledge on anaemia and injurious effect of clinical outcomes, benefits of taking Vitamin $\mathrm{B}_{12}$, iron, folate rich food and avoiding unhealthy food like junk/ fast food, will be helpful to them. It may be noted that nutritional status of a nation has a complex chain with dietary pattern as well as environment and ecology. This study principally demarcated the annual income of pond fish farmers as a vital predictor uniformly in poor society. The Government of Bangladesh should take proper steps to determine the prevalence of anaemia among the pond fish farmers. Therefore, community based health and nutrition education, immediate nutritional intervention programs, poverty alleviation program and economic growth may improve the overall health, nutritional knowledge and status of pond fish farmers enabling them to make a wiser selection of nutritious foods.

\section{Acknowledgments}

The authors acknowledge the PIU-BARC, National Agricultural Technology Programme (NATP-2, project ID: 011) for their financial support to continue the research.

Ethical approval was obtained from Noakhali Science and Technology University Ethics Committee before the commencement of study. Informed consent was also attained from local community leaders and participants.

\section{References}

Adak, D.K., R.K. Gautam, S. Bharati, A.K. Gharami, M. Pal and P. Bharati: Body mass index and chronic energy deficiency of adult males of Central Indian populations. Ann. Hum. Biol., 78, 161-179 (2006).

Ahmed, F.: Anaemia in Bangladesh: A review of prevalence and aetiology. Indian J. Publ. Hlth., 3, 385-393 (2000).

Ali, H., M.A.K. Azad, M. Anisuzzaman, M.M.R. Chowdhury, M. Hoque and M.I. Sharful: Livelihood status of the fish farmers in some selected areas of Tarakanda upazila of Mymensingh district. J. Agro. Env. 3, 85-89 (2009).

Banik, S.D.: Nutritional status of adult men from the Oraon tribe in Ranchi District of Jharkhand, India. Malays. J. Nutr., 14, $91-99$ (2008).

Biswas, T., S.P. Garnett, S. Pervin and L.B. Rawal: The prevalence of underweight, overweight and obesity in Bangladeshi adults: Data from a national survey. PLoS ONE, 12, e0177395 (2017).

De Benoist, B., M. Cogswell, I. Eglia and E. McLean: Worldwide prevalence of anaemia 1993-2005; WHO Global database of anaemia (2008).

Fagun, I. A., S.T. Rishan, N.T. Shipra and M. Kunda: Present status of aquaculture and socio-economic condition of fish farmers in a rural setting in Bangladesh. Res. Agric. Livest. Fish., 7, 329-339 (2020).

Gross, R., H. Schoeneberger, H. Pfeifer and H.J. Preuss: The four dimensions of food and nutrition security: Definitions and concepts. SCN News, 20, 20-25 (2000).

Heck, J.E., Y. Chen, V.R. Grann, V. Slavkovich, F. Parvez and H. Ahsan: Arsenic exposure and anemia in Bangladesh: A population-based study. J. Occup. Environ. Med., 50, 80-87 (2008).

Hossen, S., M.M. Ali, M.R. Sharker, N. Jahan, M.B. Hossain, Z.P. Sukhan, A. Mahmud and P. Roy: Present status of fish farming and livelihood of fish farmers in Barisal Sadar Upazila of Barisal District, Southern Bangladesh. World Appl. Sci. J., 38, 143-152 (2020).

Hyder, S.Z., L.A. Persson, A.M.R. Chowdhury and E.C. EkstroÈm: Anaemia among non-pregnant women in rural Bangladesh. Public Hith Nutr., 4, 79-83 (2001).

Hyder, S.Z., L.A. Persson, M. Chowdhury, B.O. Lönnerdala and E.C. Ekström: Anaemia and iron deficiency during pregnancy in rural Bangladesh. Public Hlth Nutr., 7, 1065-1070 (2004).

Hyder, S.Z., S.A. Chowdhury and A.R. Chowdhury: Prevalence of anaemia and intestinal parasites in a rural community of Bangladesh. Research and Evaluation Division, BRAC (1998).

James, W.P., G.C. Mascie-Taylor, N.G. Norgan, B.R. Bistrian, P.S. Shetty and A.F. Luzzi: The value of arm circumference measurements in assessing chronic energy deficiency in Third World adults. Eur. J. Clin Nutr., 48, 883-894 (1994)

Kassebaum, N.J., R. Jasrasaria, M. Naghavi, S.K. Wulf, N. Johns, R. Lozano, M. Regan, D. Weatherall, D.P. Chou, T.P. Eisele, S.R. Flaxman, R.L. Pullan, S.J. Brooker and C.J.L. Murry: A systematic analysis of global anemia burden from 1990 to 2010. Blood, 123, 615-624 (2014).

Khatun, S., R.K. Adhikary, M. Rahman, M.N.A. Sikder and M.B. Hossain: Socioeconomic status of pond fish farmers of Charbata, Noakhali, Bangladesh. Int. J. Life Sci. Biotechnol. Pharma. Res., 1, 356-365 (2013).

Khongsdier, R.: Body mass index and morbidity in adult males of the War Khasi in Northeast India. Eur. J. Clin. Nutr., 56, 484 (2002).

Lee, R.D. and D.C. Nieman: Measuring diet. Nutritional assessment. $4^{\text {th }}$ Edn., McGraw-Hill, Boston, pp. 77-114 (2007).

Llido, L.O., and R. Mirasol: Comparison of body mass index based nutritional status using WHO criteria versus "Asian" criteria: report from the Philippines. PhilSPEN Online J. Parenter. Enteral. Nutr., 1-8 (2011).

Monteiro, C.A., E.C. Moura, W.L. Conde and B.M. Popkin: Socioeconomic status and obesity in adult populations of developing countries: A review. Bull. World Hlth. Organ., 82, 940946 (2004).

Pirlich, M. and H. Lochs: Nutrition in the elderly. Best. Pract. Res. Clin. Gastroenterol., 15, 869-884 (2001).

Rahman, M., M.F. Tazim, S.C. Dey, A.K.M.S. Azam and M.R. Islam: Alternative livelihood options of fishermen of Nijhum Dwip under Hatiya Upazila of Noakhali District, Bangladesh. Asian J. Rural Dev., 2, 24-31 (2012).

Shahabuddin, A.K.M., K. Talukder, M.K. Talukder, M.Q. Hassan, A. Seal, Q. Rahman, A. Mannan, A. Tomkins and A. Costello: Adolescent nutrition in a rural community in Bangladesh. Indian J. Pediatr., 67, 93-98 (2000).

Shill, K.B., P. Karmakar, M.G. Kibria, A. Das, M.A. Rahman, M.S. Hossain 
and M.M. Sattar: Prevalence of iron-deficiency anaemia among university students in Noakhali region, Bangladesh. J. Hlth Popul. Nutr., 32, 103 (2014).

Sultana, T., M.N. Karim, T. Ahmed and M.I. Hossain: Assessment of under nutrition of Bangladeshi adults using anthropometry: Can body mass index be replaced by mid-upper-arm-circumference? PLOS ONE, 10, e0121456 (2015).

Tang, A.M., K. Dong, M. Deitchler, M. Chung, Z.M. Manasseh, A. Tumilowicz and C. Wanke: Use of cutoffs for mid-upper arm circumference (MUAC) as an indicator or predictor of nutritional and health-related outcomes in adolescents and adults: a systematic review. Washington, DC: FHI 360/FANTA. 1-6 (2013). https://www.fantaproject.org/sites/default/files/resources/MUAC \%20Systematic\%20Review\%20_Nov\% 2019.pdf

Ulijaszek, S.J. and D.A. Kerr:Anthropometric measurement error and the assessment of nutritional status. Br. J. Nutr., 82, 165-177 (1999).

UNICEF, B.: National Micronutrients Status Survey (2013).
Van Tonder, E., L. Mace, L. Steenkamp, R. Tydeman-Edwards, K. Gerber and D. Friskin: Mid-upper arm circumference (MUAC) as a feasible tool in detecting adult malnutrition. South Afr. J. Clin. Nutr., 32, 9398 (2019).

World Health Organization: Haemoglobin concentrations for the diagnosis of anaemia and assessment of severity (No. WHO/NMH/NHD/MNM/11.1). WHO (2011).

World Health Organization: Iron deficiency anaemia: Assessment, prevention and control, a guide for programme managers. Geneva, WHO (2001).

World Health Organization: Physical status: The use of and interpretation of anthropometry, Report of a WHO. Expert Committee (1995).

World Health Organization: The Asia-Pacific Perspective. Redefining Obesity and Its Treatment. Obesity: preventing and managing the global epidemic. Geneva, WHO (2000).

World Health Organization: World declaration and plan of action for nutrition. FAO (1992) 